\title{
School Indoor Environmental Quality Assessments and Interventions: Benefits of Effective Partnerships in California
}

\author{
Derek G. Shendell, MPH ${ }^{1,2}$, Michael G. Apte Ph.D., MPH ${ }^{2}$, \\ Janice Kim, MPH, MD, Ph.D. ${ }^{3}$, Svetlana Smorodinsky, MPH ${ }^{4}$
}

$1=$ University of California, Los Angeles, School of Public Health, Environmental Science and Engineering Program, 650 Charles E. Young Dr., S., 46-081 CHS, Los Angeles, CA 90095-1772 2 = Lawrence Berkeley National Laboratory, Indoor Environment Department (EETD), 1 Cyclotron Road, MS 90-3058, Berkeley, CA 94720-8132 3 = Air Toxicology and Epidemiology Section, Office of Environmental Health Hazard Assessment, California Environmental Protection Agency, 1515 Clay Street, $16^{\text {th }}$ Floor, Oakland, CA 94612

4 =Environmental Health Investigations Branch, California Department of Health Services, 1515 Clay Street, $16^{\text {th }}$ Floor, Oakland, CA 94612

\author{
Submitted, as a "commentary," to: \\ JOURNAL OF SCHOOL HEALTH
}

December 29, 2003

Word count, abstract (journal limit, 150) $=124$ words

Word count, text (journal limit, 1500) $=1000$ words (1022 with section headers).

Word count, acknowledgements with disclaimer $=165$ words

References (limit, 20) $=20$ references provided

This manuscript has no visuals.

For correspondence concerning this manuscript, please contact:

Dr. Derek G. Shendell, Senior Research Associate/Consultant-Research Scientist, Lawrence Berkeley National Laboratory (IED/EETD), 1839 Holland Drive, Walnut Creek, CA 94597-2242 (925) 788-8143 voice/(510) 486-6658 FAX

dshendel@dhs.ca.gov or derek.g.shendell.96@alum.dartmouth.org

LBNL-50377 
School Indoor Environmental Quality Assessments and Interventions:

Benefits of Effective Partnerships in California

Submitted, as a "commentary," to:

JOURNAL OF SCHOOL HEALTH 


\begin{abstract}
Public, private, government, and university stakeholders have focused increasing attention on children's environmental health. Priority areas have been healthy school environments including indoor air and environmental quality (IEQ); susceptibilities of children to environmental factors and associated illness; and, understanding exposure to biological, chemical, and physical agents. As multidisciplinary teams, studies and intervention demonstrations in California public schools were conducted. A common theme among them was a "partnership," the collaboration between stakeholders from the aforementioned sectors. Federal funding and local bond measures for planning, maintenance, and modernization of school facilities have recently been authorized. Therefore, beneficial "partnerships" should be established to conduct needed IEQ, environmental health, and productivity research, development and demonstration. This commentary describes benefits for stakeholders and five strategies for future effective collaborations.
\end{abstract}




\section{Introduction}

Completed or ongoing studies in California, ${ }^{1-7}$ Texas, ${ }^{5,7}$ Minnesota, ${ }^{8}$ and Michigan ${ }^{9}$ have focused on school indoor air and environmental quality (IEQ), respiratory health and productivity indicators, pesticide exposures, and/or ambient air quality at schools and at adjacent neighborhoods. A common theme among them was a "partnership," the collaboration between stakeholders in the public, academic, private, and government sectors. As multidisciplinary teams of environmental health scientists, epidemiologists, physicians, and engineers, we have conducted studies and intervention demonstrations in California public schools. These studies investigated IEQ, energy efficiency, and/or respiratory health through comparison of standard and advanced building envelopes, heating, ventilation, and air conditioning system technologies, and interior finish materials, or relationships between reported respiratory health and personal or environmental factors. Technician surveys, questionnaires, and indoor and outdoor air monitoring were conducted. The formation of effective "partnerships" led to varied benefits, i.e., achieving short and long-term research goals and needs of stakeholder groups.

\section{Background}

Public, private, government, and university stakeholders in the United States and abroad have focused increasing attention on children's environmental health. Priority areas include healthy school environments; susceptibilities of children to environmental factors and associated illness; and, understanding sources and routes of exposure to biological, chemical, and physical agents including molds, volatile toxic and odorous organic compounds, pesticides, and noise. Respiratory health, neurological and physical development, and academic productivity are major concerns. Children spend the majority of their time inside ${ }^{10-12}$. Since half the year a significant 
portion of this time is in school facilities, good IEQ in schools is essential. To date, school IEQ data were sparse ${ }^{13-15}$.

During the past decade, American public schools have faced many issues. Federal and state initiatives to reduce class size have targeted K-3 grade levels, with the goal of reducing the student-to-teacher ratio to 20 . Student populations have increased rapidly, especially in growing urban areas and border regions subject to immigration. Most important, public schools have faced chronic shortages of financial, technical, and human resources for overdue maintenance, modernization, expansion and/or replacement of facilities and curriculums ${ }^{16-19}$. With respect to both indoor and outdoor microenvironments, numerous concerns included:

- Playground equipment composition and safety

- Pesticide applications with associated notification and exposure issues

- Historic use of school sites, potential contamination

- Electricity crises and higher energy costs affecting quantity and quality of lighting, ventilation, and space conditioning (temperature, relative humidity)

- IEQ factors, e.g., noise levels, thermal comfort.

Good IEQ, promoted by adequate continuous ventilation with filtered outdoor air, should result in improved health and productivity. Furthermore, innovative designs can achieve these with greater energy efficiency, critical for tight budgets. Such changes are important, given environmental linkages with respiratory health outcomes. For example, although causal mechanisms of childhood asthma incidence and exacerbation are not completely understood, asthma has been the top cause of school absenteeism in the United States ${ }^{20}$. 
Collaborations Benefited Research Goals and Stakeholder Interests

Research teams and public schools

Collaborations benefited research teams by providing easier access to key local information on the communities, targeted school districts (SDs), and schools. In California studies, important information included languages to be spoken or used in recruitment letters and questionnaires, and provisions for personal safety and monitoring equipment locations, storage, and safety.

Consistent and politely repeated verbal, written, and person-to-person communications from research staff were vital in establishing and maintaining understanding and trust. This included respect for ideas, concerns, and responsibilities of SDs and school staff. Improved mutual understanding between stakeholders allowed more successful planning and implementation. Other benefits were enhanced data interpretation and means for future dissemination of results and implications. In California, pertinent research-relevant information included:

- Administrative structures and contact information

- School year calendars with vacations and standardized testing periods requiring no disruptions

- Product (manufacturer, attributes) and architect preferences

- Current environmental health and safety (EH\&S) issues including IEQ

- Relevant policies such as use of non-toxic/organic teaching materials and cleaning compounds or least toxic integrated pest management.

In California, SDs and schools appreciated the help of government and university researchers in assessing products and potential impacts on exposure, health, and productivity. 
Record keeping and oversight of school facility practices, in general, were limited, and SDs had no clear, independent way of sharing experiences.

\section{Research teams and private sector stakeholders}

Research teams understood and respected interests of private sector stakeholders. The private sector provides construction, furnishings, teaching and cleaning products, which may have specific impacts on the school or classroom environments. Human variability and errors in installation, application, use, operation and/or maintenance were recognized and expected to occur unpredictably. Although motivated by both profit and liability concerns, private companies in these sectors, when offered opportunities for research collaboration as in one

California study, ${ }^{3-5}$ were often interested in developing and/or providing improved products and advanced technologies for greater energy efficiency and improved IEQ. Collaborative interactions can also enhance documentation and feedback on safety, performance, maintenance, and durability of products and services. Cost-effective facility improvements needed by schools with finite resources should result.

\section{Summary}

The scientific community benefited from research on exposure pathways and sources at schools. Private sector stakeholder awareness of IEQ was raised. Students, teachers, principals and custodians received environmental science and health education. The practical information led to improvements in sanitation and classroom operation, which provided for early preventive interventions.

\section{Conclusions}

Federal funding and local bond measures for planning, maintenance, and modernization of school facilities have recently been authorized. For beneficial "partnerships" to conduct 
needed IEQ, environmental health, and productivity research, development and demonstration in schools, our experiences have identified key strategies for effective use of these resources.

These include:

1. Increase local knowledge about target communities, SDs, and schools.

2. Create and maintain respect and trust, and effective written and oral communications, with stakeholders during project planning, implementation, and interpretation of results.

3. Field technicians working on-site, especially in classrooms, must respect collaborators.

School environment and health assessments are dynamic; consideration of collaborator ideas improved the science.

4. Non-intrusive, non-invasive, non-disruptive protocols, coupled with environmental science, health, or energy classes for students, were successful in California.

Researchers and stakeholders working together can build, improve, operate and maintain healthy school environments. 


\section{Acknowledgements}

We thank our numerous colleagues in the successful partnerships and research described herein. We recognize the two internal and two external reviewers during preparation of this manuscript. Most important, we thank the participating school district administrators, facility directors, principals, teachers, and custodians.

This research was sponsored by a U.S. EPA STAR Graduate Fellowship (D. Shendell, \#U91-5394), CalEPA/OEHHA program projects, and the California Energy Commission through the Public Interest Energy Research program as Element 6.2.2 of the Lawrence Berkeley National Laboratory High Performance Commercial Buildings Systems research CEC Contract Number 400-99-012. The study was additionally supported by the U.S. Department of Energy under Lawrence Berkeley National Laboratory contract number DE-AC03-76SF00098.

The views expressed in this article are those of the authors. They do not necessarily represent those of the California Environmental Protection Agency, the University of California, or Lawrence Berkeley National Laboratory. 


\section{References}

1. Shendell DG, Winer AM, Stock TH, Zhang L, Zhang J, Maberti S, Colome SD. 2003a. Air concentrations of VOCs in portable and traditional classrooms: Results of a pilot study in Los Angeles County. J Exposure Anal Environ Epidemiol, in press.

2. Shendell DG, Winer AM, Weker R, Colome SD. 2003b. Evidence of inadequate ventilation in portable classrooms: Results of a pilot study in Los Angeles County. Indoor Air, in press.

3. Hodgson AT, Fisk WJ, Shendell DG, Apte MG. Predicted Concentrations in New Relocatable Classrooms of Volatile Organic Compounds Emitted from Standard and Alternate Interior Finish Materials. Berkeley, CA: Ernest Orlando Lawrence Berkeley National Laboratory, Environmental Energy Technologies Division, Indoor Environment Department, July 2001. LBNL-48490.

4. Hodgson AT, Shendell DG, Fisk WJ, Apte MG. Comparison of Predicted and Derived Measures of Volatile Organic Compounds inside Four Relocatable Classrooms due to Identified Interior Finish Sources. Berkeley, CA: E.O. Lawrence Berkeley National Laboratory, June 2003. LBNL-52520. (Also, Indoor Air, submitted for special issue.)

5. Apte MG, Di Bartolomeo D, Hotchi T, Hodgson AT, Lee SM, Liff SM, Rainer LI, Shendell DG, Sullivan DP, Fisk WJ. Simultaneous Energy Savings and IEQ Improvements in Relocatable Classrooms. ASHRAE IAQ Applications. 2003; 4 (4): 7-10. LBNL-52690.

6. California Portable Classrooms Study. http://www.arb.ca.gov/research/indoor/pcs/pcs.htm

7. Shendell DG, Apte MG, Corsi R, Jenkins M, Kim J, Smorodinsky S, Torres V, Waldman JM. "Studying the Public School Environment and Classroom Indoor Air Quality: Communitybased Exposure Assessments Through Public-Private-Government Partnerships, Examples 
from CA and TX." $11^{\text {th }}$ Annual Meeting of the International Society of Exposure Analysis, Charleston, SC, November 4-8, 2001.

8. Sexton, K, Greaves, IA, Church, TR, Adgate, JL, Ramachandran, G, Tweedie, RL, Fredrickson, A, Geisser, M, Sikorski, M, Fischer, G, Jones, D, and Ellringer, P. A SchoolBased Strategy to Assess Children's Environmental Exposures and Related Health Effects in Economically Disadvantaged Urban Neighborhoods. J Exposure Anal Environ Epidemiol. 2000; 10 (6, Part 2): 682-694.

9. Keeler, GJ, Yip, FY, Morishita, M, Barres, JA, Robins, TG, Dvonch, JT, Parker, EA, Israel, BA, Marsik, FJ, Brakefield-Caldwell, W, and Sam, M. Personal Exposures to Particulate Matter Among Asthmatic Children in Detroit, MI. $11^{\text {th }}$ Annual Meeting of the International Society of Exposure Analysis, Charleston, SC, November 4-8, 2001.

10. Wiley, JA, Robinson, JP, Cheng, YT, Piazza, T, Stork, L, and Pladsen, K. 1991. Study of Children's Activity Patterns. Final Report, ARB Contract No. A733-149. University of California, Berkeley, CA.

11. Klepeis, NE, Nelson, WC, Ott, WR, Robinson, JP, Tsang, AM, Switzer, P, Behar, JV, Hern, SC, and Engelmann, WH. The National Human Activity Pattern Survey (NHAPS): a resource for assessing exposure to environmental pollutants. J Exposure Anal Environ Epidemiol. 2001; 11 (3): 231-252.

12. Zmirou, D, Gauvin, S, Pin, I, Momas, I, Just, J, Sahraoui, F, Le Moullec, Y, Brémont, F, Cassadou, S, Albertini, M, Lauvergne, N, Chiron, M, Labbé, A, and VESTA investigators. Five Epidemiological Studies on Transport and Asthma: Objectives, design, and descriptive results. J Exposure Anal Environ Epidemiol. 2002; 12 (3): 186-196. 
13. Daisey, JM, Angell, WJ, and Apte, MG. Indoor Air Quality, Ventilation and Health Symptoms in Schools: An Analysis of Existing Information. Indoor Air. 2003; 13 (1): 53-64. LBNL-48287.

14. Heath, GA and Mendell, MJ. Do Indoor Environments in Schools Influence Student Performance? A Review of the Literature. Proceedings of the $9^{\text {th }}$ International Conference on Indoor Air Quality and Climate, Indoor Air 2002, Monterey, CA, June 30-July 5, 2002.

15. Wakefield, J. Learning the Hard Way: The Poor Environment of America's Schools. Environ Health Perspect. 2002; 110 (6): A298-A305.

16. U.S. General Accounting Office (USGAO). 1995. School Facilities: Conditions of America's Schools. Washington, D.C. GAO/HEHS-95-61.

17. USGAO. 1996a. America’s Schools Report Differing Conditions. Washington, D.C. GAO/HEHS-96-103.

18. USGAO. 1996b. School Facilities, Profiles of School Conditions by State. June 1996. Washington, D.C. GAO/HEHS-96-148.

19. Schmidt, CW. Reading, Writing, but no Arithmetic: Healthier Schools Legislated but Funding Lags. Environ Health Perspect. 2002; 110 (6): A298-A305.

20. Mannino, DM, Homa, DM, Akinbami, LJ, Moorman, JE, Gwynn, C, and Redd, SC. Surveillance for Asthma—United States, 1980-1999. MMWR. March 29, 2002; 50 (SS01): $1-13$. 